\title{
MODELS FOR CONTEMPORARY EXPLOITATION OF BALNEOLOGICAL POTENTIAL IN VOJVODINA
}

\author{
DOI: 10.18485/arh_pt.2020.7.ch28
}

\section{_ Nataša Ćuković Ignjatović}

Associate Professor, University of Belgrade - Faculty of

Architecture, Bulevar kralja Aleksandra 73/II, natasa@arh.bg.ac.rs

\author{
_ Dušan Ignjatović \\ Associate Professor, University of Belgrade - Faculty of Architecture, \\ Bulevar kralja Aleksandra 73/II, Ignjatovic.dusan@arh.bg.ac.rs
}

\section{ABSTRACT}

Due to its geological specificities, Vojvodina is abundant with various balneological resources. During 2018, an extensive multidisciplinary research was conducted in order to investigate the current condition on 50 sites, explore the quality and quantity of relevant resources and offer proposals for developing contemporary balneology facilities. The architectural programs spanned from modest drinking fountains to complex developments and resorts with variety of facilities. Throughout the process, a series of model units were developed and tailored to match the medical and therapeutical requirements with the imperatives of environmentally conscious, sustainable and resilient architecture.

Typological and modular approach was identified as the most efficient both for effective development and construction in various circumstances as well as for promoting the balneology as a rediscovered potential for healthcare tourism, well-being and revival of some local communities. Site-specific architectural design is perceived as one of the key premises of green architecture; however, the topology of Vojvodina planes has enabled the development of modular units that are easily adjusted to the specific site. These units were developed aiming to achieve different functional and esthetical variations using the same basic structure, building principles and components. Furthermore, this approach enables seasonal variations and optimisations in facility's capacity, allowing the permanent, year-round operation avoiding unnecessary operation costs and maintaining favourable ecological footprint. Finally, by using the optimised units for potential extensions, maintaining and improving of building performance is secured, while keeping recognizable and uncompromised architectural language throughout facility's life span. The use of passive design features and on-site renewable energy resources (solar and geothermal) was also taken into the consideration from the conceptual design phase. The paper systematically presents the scope and achieved results of the research process with an overview of selected case study examples showing the application options in various conditions.

KEYWORDS_balneology, green architecture, resilient architecture, healthcare, well-being

\section{INTRODUCTION}

The World Health Organisation defines health as "a state of complete physical, mental and social well-being and not merely the absence of disease or infirmity" (WHO, 1948) stating that "the enjoy- 
ment of the highest attainable standard of health is one of the fundamental rights of every human being". These points are often overcast by the daily challenges of fighting diseases and infirmities, coupled with the weaknesses of the healthcare system. Regions rich in thermomineral waters have a unique potential for achieving sustainable advancements in public health with various benefits for the community and local economy (Toth et al, 2015), directly and indirectly addressing a series of UN sustainability goals (UN 2015). The paper presents research in sustainable and resilient architectural design models suitable for developments of various balneal facilities in Vojvodina, agricultural region in northern Serbia.

Balneology, though known for its medical benefits from the ancient times, currently is going through the transition both in terms of its place in formal medical science as well as in terms of being recognized as a valuable asset in context of tourism, development of local and even state economies and improvements of general well-being of the population. Contemporary definitions of medical tourism encompass medical travel, recreational travel and traveling for other purposes (Schmerler 2018). All of the stated aspects are highly relevant for balneo therapy, which, by its nature, can successfully meet the variety of their needs if provided with adequate infrastructure. Serbia is particularly rich in mineral, thermal and thermominaral waters with sites recognized and in use ever since the Roman Empire (Protic, 1995). The same hydrogeological resources show great potential for use of hydrogeothermal energy (Dokmanović et al, 2012), thus providing convenient energy source that could be used for achieving high level of energy efficiency in all sorts of spa facilities.

Vojvodina is placed in Pannonian basin, which, due to its hydrogeological specificities, is abundant with various balneological resources which has resulted in development of various facilities and resorts throughout the region, and the current trends have also been a driver for recent research in this area aiming to:

- assess the capacity and potential on already known sites,

- detect new sites, asses their medical and hydrological potential,

- propose contemporary and sustainable models for exploitation of balneological resources.

During 2018, an extensive multidisciplinary research was commissioned by the Provincial Secretariat for Economy and Tourism of AP Vojvodina in order to investigate the current condition on 50 sites in Banat, Srem and Backa, explore the quality and quantity of relevant resources and offer proposals for developing contemporary balneology facilities. The samples, collected as a part of hydrogeological research, were analysed in specialised laboratory and the results were forwarded to the specialist at the Faculty of Medicine in order to determine the medical potential (healing factor) of each resource and propose the adequate balneo therapy options. The research was preceded by the study of balneological potential of Vojvodina (Milenic et al. 2017) which involved extensive geological research resulting in identification of numerous sites of interest and definition of zones with significant potential.

The architectural programs, derived from the multidisciplinary research and conceived as illustrative proposals for potential developments on the site, spanned from modest drinking fountains to complex resorts with variety of facilities. Since the design proposals referred to on-site use of the balneological resource, the character of the sights also varied greatly, from facilities placed within urban or rural settlements, to, sometimes rather remote sites with poor or no infrastructure. Throughout the process, a series of model units were developed and tailored to match the medical and therapeutical requirements with the imperatives of environmentally conscious, sustainable and resilient architecture. The paper presents design premises and methods as well as design strategies developed for the balneo facilities in Vojvodina and applied on a number of selected cases.

\section{DESIGN PREMISES AND METHODS}

Design premises were based in line with the UN sustainability goals, where sustainable and resilient architecture for healthcare and spa facilities was conceived as the driver for circular economy and 
improved well-being of local population. Design approach was tailored in regard with several factors, as shown in Table 1.

_ Table 1 An overview of balneo facilities included in the study

\begin{tabular}{|c|c|c|c|c|c|c|c|c|c|c|c|}
\hline \multirow{2}{*}{ facility } & \multicolumn{3}{|c|}{ urban context } & \multicolumn{2}{|c|}{ status } & \multicolumn{3}{|c|}{ accommodation } & \multicolumn{3}{|c|}{ seasonal sensitivity } \\
\hline & $\mathbf{T}$ & v & $\mathbf{R}$ & $\mathrm{N}$ & $\mathrm{R} / \mathrm{C}$ & s & v & N/A & H & M & $\mathbf{L}$ \\
\hline $\begin{array}{l}\text { public fountain } \\
\text { (drinking water) }\end{array}$ & 2 & 9 & 4 & 9 & 6 & & & 15 & & 5 & 10 \\
\hline $\begin{array}{l}\text { public bath } \\
\text { (balneo baths) }\end{array}$ & 1 & 3 & 1 & 4 & 1 & & & 5 & 1 & 2 & 2 \\
\hline $\begin{array}{l}\text { wellness \& spa } \\
\text { facilities }\end{array}$ & 10 & 3 & 7 & 13 & 7 & 6 & 7 & 7 & 6 & 9 & 5 \\
\hline mud extraction & & & 3 & 2 & 1 & & & 3 & 3 & & \\
\hline $\begin{array}{l}\text { aqua park (with } \\
\text { thermomineral) }\end{array}$ & 1 & & 2 & 3 & & & & & 3 & & \\
\hline \multirow[t]{4}{*}{ other } & 2 & & 2 & 2 & 2 & 1 & & 3 & 2 & 2 & \\
\hline & \multicolumn{3}{|c|}{$\mathbf{T}=$ town } & \multicolumn{2}{|c|}{$\mathbf{N}=$ new } & \multicolumn{3}{|c|}{$\mathbf{S}=$ provided on site } & \multicolumn{3}{|c|}{$\mathbf{H}=$ high } \\
\hline & \multicolumn{3}{|c|}{$\mathbf{V}=$ village } & \multirow{2}{*}{\multicolumn{2}{|c|}{$\begin{array}{l}\mathrm{R} / \mathrm{C}=\text { existing or } \\
\text { new } \\
\text { complimentary }\end{array}$}} & \multirow{2}{*}{\multicolumn{3}{|c|}{$\begin{array}{l}\mathbf{V}=\text { provided in the vicinity } \\
\mathrm{N} / \mathrm{A}=\text { not needed }\end{array}$}} & \multirow{2}{*}{\multicolumn{3}{|c|}{$\begin{array}{l}\mathbf{M}=\text { medium } \\
\mathbf{L}=\text { low }\end{array}$}} \\
\hline & $\mathbf{R}=\mathrm{re}$ & e site & & & & & & & & & \\
\hline
\end{tabular}

The core design principles were applied in all cases but the focus of this paper will remain on wellness \& spa facilities since they show most diversity in terms of urban context, status, offer of (or need for) an accommodation and seasonal sensitivity. The design strategies were defined for sites placed within the settlements and on the remote locations, new (greenfield) projects or providing additional facilities for existing ones, with or without accommodation and other hospitality functions, and with high, medium or low seasonal dependence.

The issues of sustainability and resilience were addressed on several levels:

_ program - defined to be sensitive to local needs and capacities, conceived for gradual development (reflected on various design aspects);

_ adaptive capacities - aimed to enable year-round functioning having in mind seasonal changes, as well as prospective changes (anticipated and unexpected) throughout the facility's lifespan;

_ infrastructural independence - aiming for off-grid functionality, especially for the remote sites;

_ carbon footprint - aiming for carbon-neutral developments;

_ local production - supported by the choice of proposed building technology and materials. While resource efficiency in terms of material use and reference to $3 R$ (reduce, reuse, recycle) concepts remained as general design goals, specific design strategies were proposed in the domain of energy efficiency, stressing the impact of architectural design on minimizing energy demand, thus enabling to aim the coverage from on-site (renewable) energy sources. Program-specific energy efficiency design strategies were defined focusing on a wide range of passive design measures while integrating the technology related to necessary active systems from the conceptual design phase. Water management in these facilities is very dependent on the water composition, flows and temperatures and yet needs to be dealt with extreme delicacy in order to preserve unique hydrogeological characteristics so it needs to be treated on case-by-case basis. All proposals were designed with extreme caution to maximising porous surfaces, minimising the potential contamination of surface water and recommendations for rainwater collection and use where appropriate. 


\section{DESIGN STRATEGIES - RESULTS AND DISCUSSION}

Design goals were addressed through a variety of design strategies, which were applied on 20 sites with wellness \& spa facilities sized from small mobile units for balneal treatments to complex multifunctional developments. The main design strategies included:

- modularity

_ sizing and positioning of open-air and indoor features

_ passive design

_ use of on-site renewable energy sources.

\section{Modularity}

Structuring the program into modular units has proven to be a very powerful and effective design tool for accomplishing several of design goals set for this study. While easily enabling programmatic diversification and flexibility, the modular approach could also open the door for local production of prefabricated elements, technologically manageable by small and medium enterprises.

Carefully planned and positioned modules allow phase execution, significantly reducing the initial construction costs. This is even more important when local community is financing or co-funding the facility since the median value of overall costs for 20 proposals included in the study (excluding the land, which is already publicly owned) is estimated to be approximately EUR $1,500,000$. Only two of them were designed as single multifunctional buildings (total area $300 \mathrm{~m} 2$ and $1000 \mathrm{~m} 2$ ) due to the specific site and programmatic conditions.

Interconnected modules, which can individually be included to or excluded from the facility's current operation, allow very economic operation in reduced capacity as well, which is very important, having in mind that 15 out 20 facilities were characterised as significantly dependant on the season, meaning that with this concept they all may remain open for public all year round with optimised operational costs.

Modular approach, sequencing visually and functionally almost isolated open-door and enclosed spaces provides layout with high level of privacy, minimizing the contacts between the users of different treatments while allowing optimal hygiene and maintenance intervals during the operating hours.

Modular design also allows for expansion of the capacities beyond the initial plans whilst retaining the original design features, or remaining at the reduced number of constructed modules for long period in case of unfavourable economic, social or climate conditions. Figure 1 shows the example of rather modest initial development ( 3 modular units with proper common and utility spaces). Regarding the site conditions - area, topology and overall feasibility, the expansions can be anticipated mainly along East-West axes in two basic scenarios:

1) Planning the phases (anticipated capacities during the development period), where the majority of auxiliary/technical spaces are planned according to the final capacity and modular units and adjacent programs (medical and/or hospitality) are executed in stages.

2) Open development, where the majority of auxiliary/technical spaces are planned according to the initial capacity with the main layout features are designed to support additional extensions until reaching the full capacity of a given site.

Simple layout and structure of individual modules makes them very flexible, allowing for partial adaptations, changes of use or even regaining the functionality after extreme catastrophic events and severe material damages.

The general concept allows optional additions of adjacent hospitality and/or medical facilities (Figure 1). However, such facilities might be planned with different, program-specific design strategies and they are not further discussed at this stage of research. 


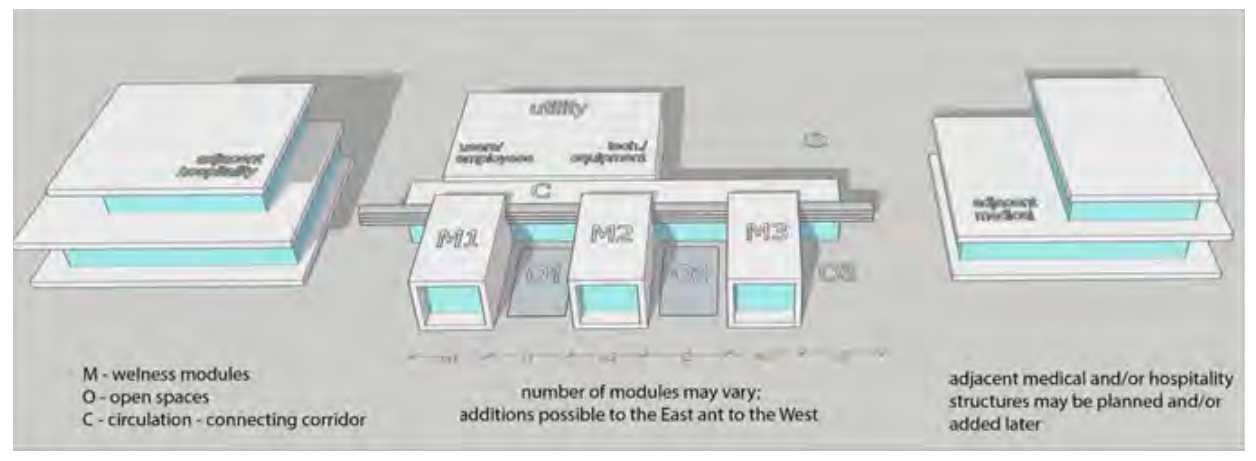

_ Figure 1: Model for modular wellness facilities

\section{Sizing and positioning of open-air and indoor features}

General placement and interconnections of open-air features and built structures was proposed through holistic design approach, taking into consideration functional demands, passive design principles, and advantages of modular approach described in the previous section. The presented design strategies were developed having in mind the specific nature and demands of wellness and spa features that incorporate balneo therapy as well as the hydrogeological potential of those sites. Open-air and indoor features were purposely sized and organized in a way that allows shared use of auxiliary spaces, i.e. reception, changing rooms, lockers, service rooms etc. (Figure 1). The therapy functions are distributed throughout the open-air and enclosed spaces in a way that allows their compatibility and provides a continuity of various treatments in different weather scenarios. This enables extended operation time, mitigating the sensitivity to seasonal/annual variations in climate while optimizing running costs.

The most of open-air features are rather small in size, following the general concept of modularity and phase execution and operation. The width $\mathrm{i}$ of intermediate open-air spaces 0 may vary in regard to the height of the neighbouring modules M (Figure 1), functional and privacy requirements. Additional screens may be added for enhanced privacy and additional sun protection of intermediate open spaces.

The modest capacities of both enclosed and open-air spaces allow local production for less specific types and less demanding maintenance which may be one of the actual preconditions for sustainability of such features in small communities.

Passive design strategies

Striving for high level of energy efficiency and climate-responsive design, a series of passive design strategies were proposed to support the overall design goals.

Placement and orientation: Placement of all open-air features and enclosed spaces was done in way that provide optimal daylighting, solar exposure and shading (Figure 1, Figure 2). North-facing sections are used for technical rooms, storages, sanitary spaces etc. Circulation corridors connecting the modules are also placed on the Northern side, leaving the South-facing open-air spaces between the modules, sheltered and functionally supported by the side volumes. Longitudinal circulation space can be open or enclosed with glazed south-facing walls, serving as buffer space for modules.

Massing, solar gains and shading: Modules are compact in shape in order to provide good shape factor for each unit. The same principles were applied to all public and utility spaces except for the longitudinal circulation corridor. Modular units and corridor are mainly opaque on the North façade for improved thermal performance and almost fully glazed on the South façade for maximising solar gains. Adequate shading was provided by various design features (Figure 2) tailored to provide unobstructed views in various weather conditions and additionally supported with adequate choice of glazing and flexible interior shading. 
Natural ventilation and cooling: Glazed surfaces are designed with the intention to maximise the share of operable elements with cross-ventilation provided for all spaces. The basic layout, as described previously in this chapter, provides very good preconditions for natural ventilation and effective application of night cooling, further enhanced by the green areas and water features. In favourable weather conditions, the glazed façade of the long corridor can be open along the intermediate semi-atrium spaces.

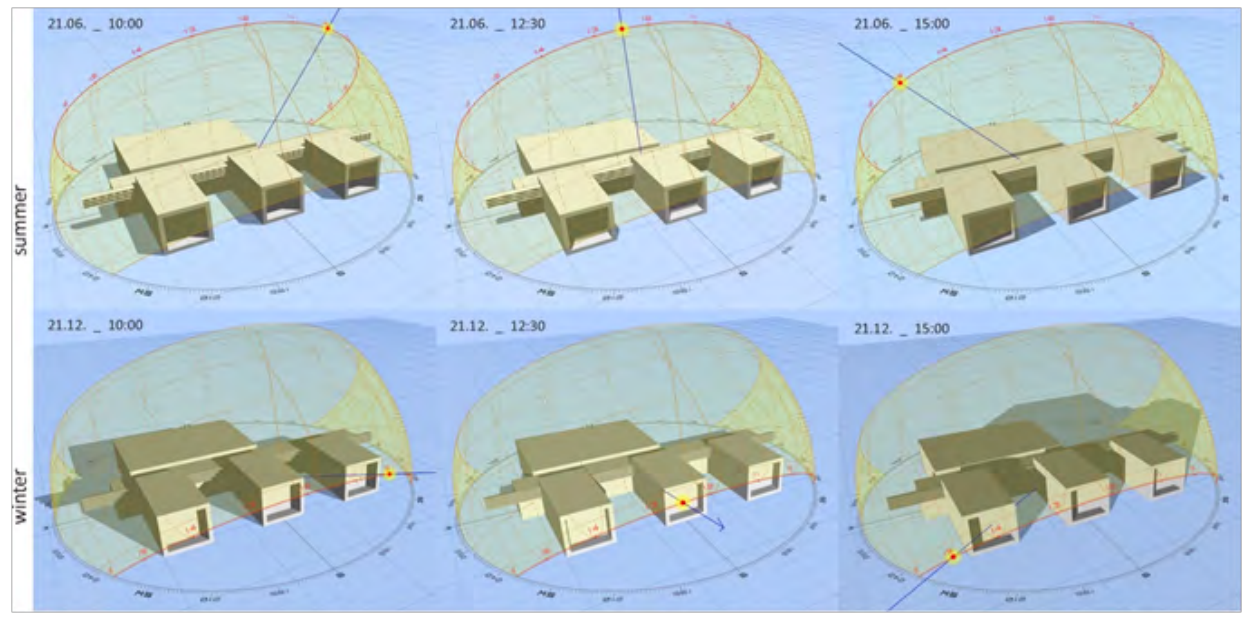

_ Figure 2 Solar exposure and shading: all glazed surfaces of wellness modules and circulation volume are fully shaded during summer to prevent overheating and almost completely exposed during winter to enable direct passive solar gains

Thermal mass and materials: The modules are designed as lightweight structures where low thermal mass is used for optimising the comfort and energy efficiency in intermittently used spaces. Enhanced thermal insulation and high-performance glazed element could significantly contribute to further mitigation of energy demands for cooling and heating. The façade and roof finishing also affect the energy efficiency but they should be considered in case-by-case basis. In exposed sites, with the peak occupancy in summer season, reflective surfaces or green roofs should be prioritized. In more secluded sites, structures surrounded by deciduous trees (naturally shaded in summer and exposed in winter), reflectiveness is not so much of an advantage.

Use of on-site renewable energy sources (RES)

Striving for high level of energy efficiency and self-sustainability, two main on-site RES were considered: geothermal (hydrogeothermal) and solar (PV).

The largest number of wells that capture mineral waters in the area of Vojvodina has an outlet temperature in the range of $40-600 \mathrm{C}$ (Milenic et al. 2017) which enables direct use of geothermal energy for space heating and sanitary hot water. Abundance of hydrogeothermal resource on these sites might allow instalment of completely independent system, providing a reliable off-grid energy source for the entire facility in most occupancy regimes.

Solar potential is rather constant on the territory of Vojvodina, with total annual solar irradiation averaging around $1400 \mathrm{kWh} / \mathrm{m} 2 /$ an, and monthly values of over $100 \mathrm{kWh} / \mathrm{m} 2 / \mathrm{mo}$ for March through October (as calculated using PVGIS software). This indicates that significant amounts of electric energy can be generated on-site, supporting the water filtration and other technical systems in their full capacity (during the main tourist season), thus complete energy independence could be targeted on the sites where such approach might be necessary or feasible in given circumstances. 


\section{CONCLUSIONS}

Balneological resources are recognized for their tourist potential and may be used as drivers for development, especially as is the case in some municipalities in Vojvodina. The presented model for wellness\&spa facilities for the sites with identified thermomineral resources is based on modular approach, designed primarily for initial steps for contemporary exploitation, often to be financed or strongly supported by the local authorities, with limited financial resources and capability for long-term strategies. Design strategies presented in the paper (modularity, sizing and positioning of open-air and indoor features, passive design features), combined with the use of on-site renewable energy sources enable high level of sustainability, resilience, energy independence, offering extended operational options, adaptable to seasonal, weakly and even daily changes in use. The flexibility is allowed for construction phases as well, adapting to predicted and unpredicted needs and development conditions, use of local manufacturers which is of great importance in less developed areas, facing constant depopulation.

\section{REFERENCES}

- Dokmanović, Petar B., Krunić, Olivera Ž., Martinović, Mića K., and Magazinović, Sava M. 2012. "Hydrogeothermal Resources in Spa Areas of Serbia: Main Properties and Possible Improvement of Use". Thermal Science Vol. 16, No. 1, pp. 21-30

- Milenić, D., Krunić, O., Vranješ, A., 2017. Balneological Potential of the Territory of AP Vojvodina - Resource Research, Multiparameter Valorisation and Directions of Development (in Serbian), Scientific study. Belgrade: University of Belgrade - Faculty of Mining and Geology

- Protić, D., 1995. Mineral and Thermal Waters of Serbia (in Serbian), Geoinstitut, Special editions, vol. 17 , Belgrade, Serbia, p.35

- Schmerler, Klaus. 2018. Medical Tourism in Germany: Determinants of International Patients' Destination Choice. Cham: Springer

- Szokolay, Steven. 2004. Introduction to architectural science: the basis of sustainable design. Oxford: Architectural Press

- Toth, Aniko N., Sztermen, Aniko, Fenerty, David K. 2015. "Social Acceptance of Geothermal Energy Through Tourism and Balneology" in Proceedings World Geothermal Congress 2015 Melbourne

_ $* * *$ United Nations. 2015. Transforming our world: the 2030 agenda for sustainable development. A/ $\mathrm{RES} / 70 / 1$

_ $* * *$ World Health Organization. 1948. Constitution of the World Health Organization 